\title{
Bloom fading from e-health golden wattle
}

I t sounded like a great idea in 2010: a personally controlled electronic health record that would allow Australians to access and share medical records in a nationwide database. The system, it was argued, would support better medical decisionmaking, reduce errors and save time and money.

To that end, the government set aside A\$467 million and targeted an ambitious launch date of July 1, 2012.

Medical groups such as the Australian Medical Association lauded the notion, asserting that a shared electronic health record would help doctors deliver better care as they'd have access to a patient's full clinical records no matter where he was treated. Health and consumer advocates were equally effusive. The proposed system would yield improved health outcomes, reduce medical mistakes and provide confidential health records.

But as details emerge and the launch date nears, the supposed charms of a Personally Controlled e-Health Record (PCEHR) appear to be fading, much as the bloom eventually withers on Australia's national flower.

"E-health in general is a good idea, but you need some other infrastructure and you need it to be comprehensive," says Robert Wells, director of the Australian Primary Health Care Research Institute. "In my view it's a complete waste of money and I'm not sure what they hope to achieve from it."

What has changed so dramatically in a few scant years?

As now envisioned, patient interaction with the system will be much more limited. The federal Health Department has admitted there will be privacy risks in the transfer of patient data. And a recent Senate inquiry indicated that the software, as well as the architecture that will allow patients and clinicians to join the network and share data, may not be ready on time.

"There is still some very signifi-

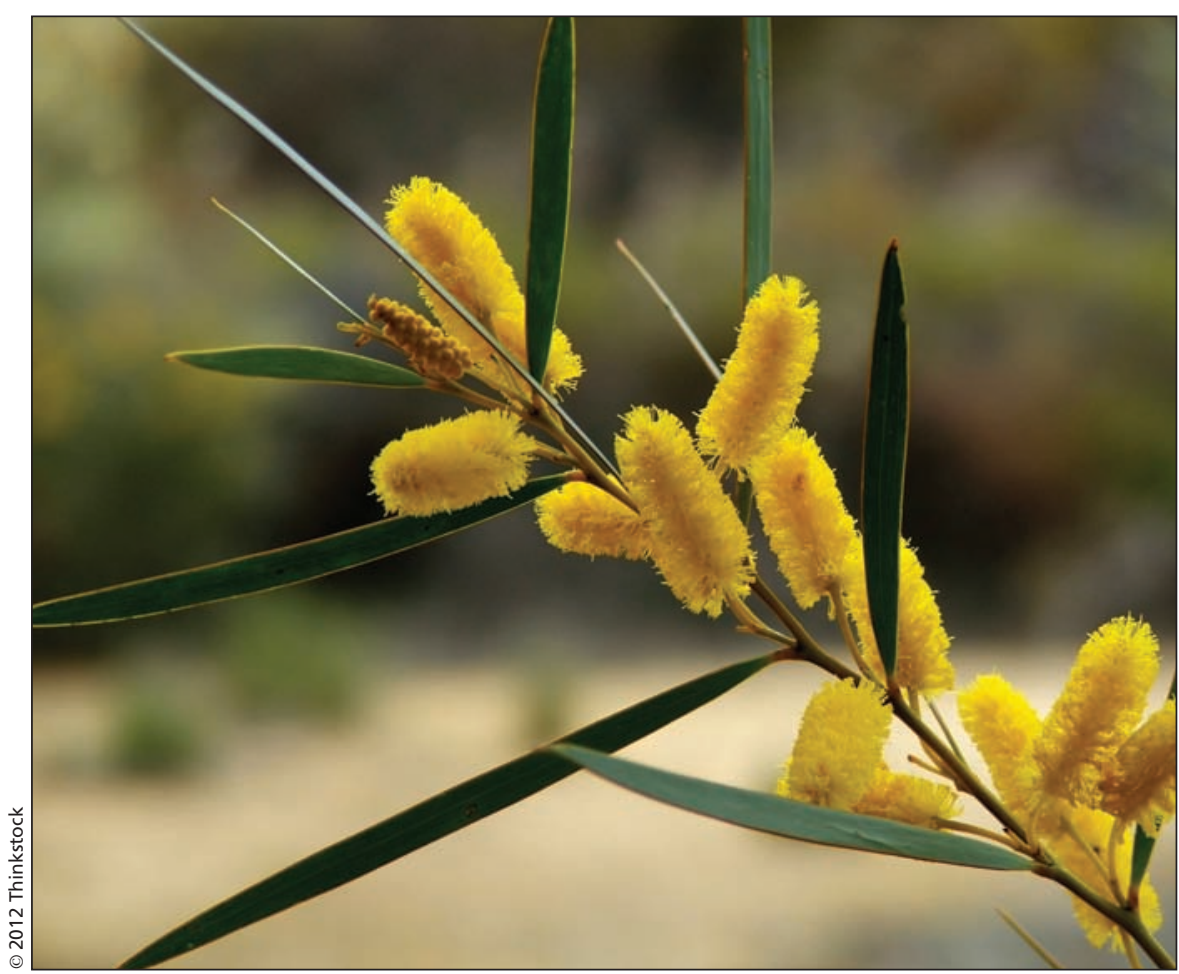

As details emerge about Australia's personally controlled e-Health record system, its charms appear to be fading, much as the bloom eventually withers on the country's national flower, the golden wattle.

cant development work to be done on the PCEHR functionality," Rosemary Huxtable, deputy secretary with the Department of Health and Ageing, told parliamentarians.

Because of that lack of "functionality," the Australian Medical Association and the Health Care Consumers' Association have expressed consternation about the timing of the system's rollout, while a coalition of senators is urging that the venture be delayed for 12 months.

Health Minister Tanya Plibersek has downplayed concerns, telling reporters that the PCEHR will eventually come together. "Over time, the system will join the dots electronically between GPs [general practitioners], pharmacists, specialists, allied health professionals, hospitals and patients." Plibersek also flatly denied reports that costs have blown out to A\$760 million.
As for privacy concerns, Australian security experts are warning that insufficient security protections could leave the system open to hacking.

The health department insists clinical data will be encrypted during transmission but acknowledges that it could be compromised at the personal computer level. To combat that, the department says it will issue instructions to users as to how to protect themselves from security threats.

Others are now struggling to comprehend whether the system, as currently envisioned, will have any benefits.

The main problem is that the system isn't compulsory, Wells says, noting that patients and health professionals must choose to "opt in," rather than "opt out," as had been recommended by the Australian Medical Association. An opt-out model would have ensured that the benefits accrued to the elderly, to indigenous peoples and to those with 
chronic conditions, all of whom, the association argued, are the least likely to know that an electronic health record system was in place.

In any electronic health record system, value increases with the number of people enrolled, Wells notes. "I think the real benefit in electronic records is that they can follow the patient around through the system and create some efficiencies in terms of unnecessary ordering of tests, repeating information and things like that."

Moreover, even if Australia's personally controlled electronic health record system is in place by July, it will only offer summary, rather than detailed and comprehensive, patient records. And patients will have limited access and limited opportunity to provide input, at least initially.

"I think providers of care will say, 'Why would you bother?' At best it has extremely limited use," Wells said.

The proposition is supported by developments in Great Britain, which similarly saw an extremely low "optin" rate, and which dismantled its system after experts deemed it wasteful and flawed (www.cmaj.ca/lookup/doi /10.1503/cmaj.109-4001).

An ideal e-health plan would reduce costs for funders, reduce liability risks for physicians and bolster a patient's ability to share in the management of his health records, says Klaus Veil, vice president of the Australasian College of Health Informatics.

But as currently configured, the personally controlled electronic health record that will become operational in July is not capable of "doing the job," Veil says. "Core bits are missing. We don't know if and when this functionality will actually be in the PCEHR." Tanalee Smith, Adelaide, Australia

CMAJ 2012. DOI:10.1503/cmaj.109-4180 